
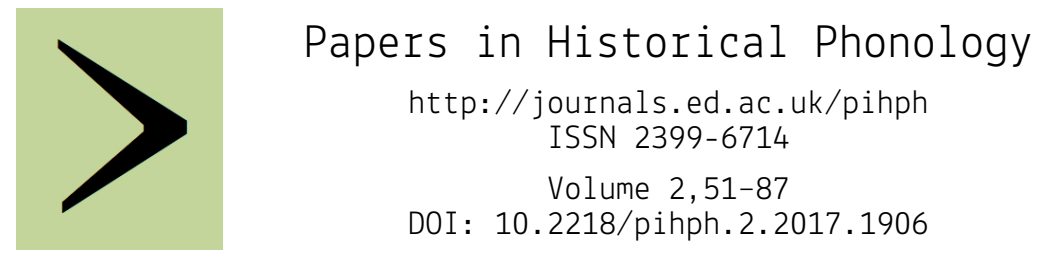

DOI: $10.2218 /$ pihph.2.2017.1906

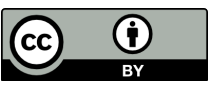

Licensed under a

Creative

Commons 4.0

International

License

\title{
Lexical tone in Deori: loss, contrast and word based alignment
}

\author{
SHAKUNTALA MAHANTA \\ Indian Institute of Technology, Guwahati \\ INDRANIL DUTTA \\ The English and Foreign Languages University, Hyderabad \\ PRARTHANA ACHARYYA \\ Indian Institute of Technology, Guwahati
}

\begin{abstract}
In this paper we investigate the existence of tones in Deori, a language which is historically known to have had tonal distinctions. In a study, 5 speakers were recorded for their production of potential lexical tones in a list of 34 words, and a list of 54 monosyllabic roots were recorded for a vowel experiment. We conducted an f0 analysis in order to examine the extent of 'tonoexodus' and loss of tonal properties in Deori. To the extent that experimental methods can be used to determine lexical tone, phonetic measurements of f0 and further statistical analysis reliably indicate the distribution of lexically distinct tones. The results show clear presence of tonally distinctive words but without any definitive tonal alignment. We consider the diachrony and synchronic analysis of this and conclude that the syllable is not the Tone Bearing Unit in the conventional sense in current Deori, and that there is no clinching evidence to suggest alignment and spreading of the lexically distinctive tone to the right edge. Given these results, we conclude that tone is spread in the entire word in Deori. We also note that Deori no longer exhibits the prototypical Tibeto-Burman sesquisyllabic pattern and has instead developed an iambic stress pattern.
\end{abstract}

\section{Introduction}

Tone languages employ pitch differences to distinguish otherwise segmentally similar lexical entries. Pitch is one of the major characteristic features of phonologically distinctive tones in many languages of the world, and tone is naturally subject to diachrony, like all other aspects of phonological structure. The dominant view on 
tonogenesis is that tones typically arise endogenously from consonantal changes and neutralizations (Haudricourt 1954, Matisoff 1973a, Mazaudon 1977, Abramson 2004). Continuous interaction with neighbouring languages often leads to the borrowing of lexical items and grammatical features, and can shape the pronunciations of the speakers of those neighbouring languages. A language may thus also acquire tone due to an areal effect (Gussenhoven 2004). In this paper we focus on aspects of 'tonoexodus', as discussed below: areal effects can also lead to the loss of tone, and tone can be lost endogenously, too.

Deori is a Tibeto-Burman language belonging to the Boro-Garo subfamily within that group. The Tibeto-Burman language family shows great variety in its linguistic features. Tone is one of the distinguishing features in Tibeto-Burman languages, albeit with a great amount of variety. There are languages like Loloish which are monosyllabic and analytic with tone marked on every syllable, and others like the Kiranti group spoken in Nepal where tone is only marginally present (Matisoff 2003). Most of the Tibeto-Burman languages spoken in the Assam valley in India are known to have tonally distinct lexical entries where the domain of tone is the word and not the syllable (see also Mazaudon 2014, for Kammu).

In this paper we examine the extent to which Deori has lost tones diachronically, given that there have been reports of tonal mergers and/or loss for the language. We report the results and analysis of a controlled phonetic experiment which investigated a set of words which have previously been reported to have lexically contrastive tones. Tonal anchoring, however, was a difficult problem to resolve, and therefore we conducted further examination of some minimal pairs to arrive at a conclusive understanding of tonal phenomenon in Deori. Although this paper is primarily concentrated on the tonal properties of Deori, we have also carried a significant amount of work on the phonetic description of Deori vowels. It was important to undertake this work to understand the nature of Deori vowels and the extent to which they play the role of the tone bearing unit in Deori.

The structure of the paper is as follows. Section 1 presents some background about Deori in the context of its place in the Tibeto-Burman language family. In this context, section 1.2 presents an introduction to 'tonoexodus' in the light of recent studies on the phenomenon. Section 2 discusses the vowel phonemes in Deori and also presents the results of an experiment showing the presence of five contrastive vowel phonemes in the language. This section also presents the results of vowel duration comparisons and concludes that Deori shows an iambic stress pattern. Section 3 is about Deori tones: the three sub sections in this section present the process of data collection, fieldwork, data 
processing and statistical analysis and discussion of these results. The concluding section in 3.3 summarizes the main findings of our experiments in the context of potential tone loss in Deori.

\subsection{The Deori Language}

Deori Chutiya is a small and secluded tribe and primarily a farming community settled in Deori villages in the districts of Lakhimpur, Dhemaji, Dibrugarh, Jorhat, Tinsukia, Sonitpur and Sivsagar. In the Encyclopaedia of the World's Endangered Languages (Moseley 2007), Deori is listed as an endangered language. According this report, the number of speakers are 27,960.

The Deori community has been divided into three main groups Dibongiya, Tengapani, and Borgonya. Of these three divisions, at present, only the Dibongiyas speak the Deori language (Goswami 1994). The Dibongiyas mainly reside in Bor Deori village, Narayanpur , a town located in Lakhimpur district and in Naam Deori and Upor Deori villages in Jorhat. During the research conducted for this paper, both the Naam Deori village in Jorhat and the Bor Deori village in Lakhimpur were visited for the purpose of data collection.

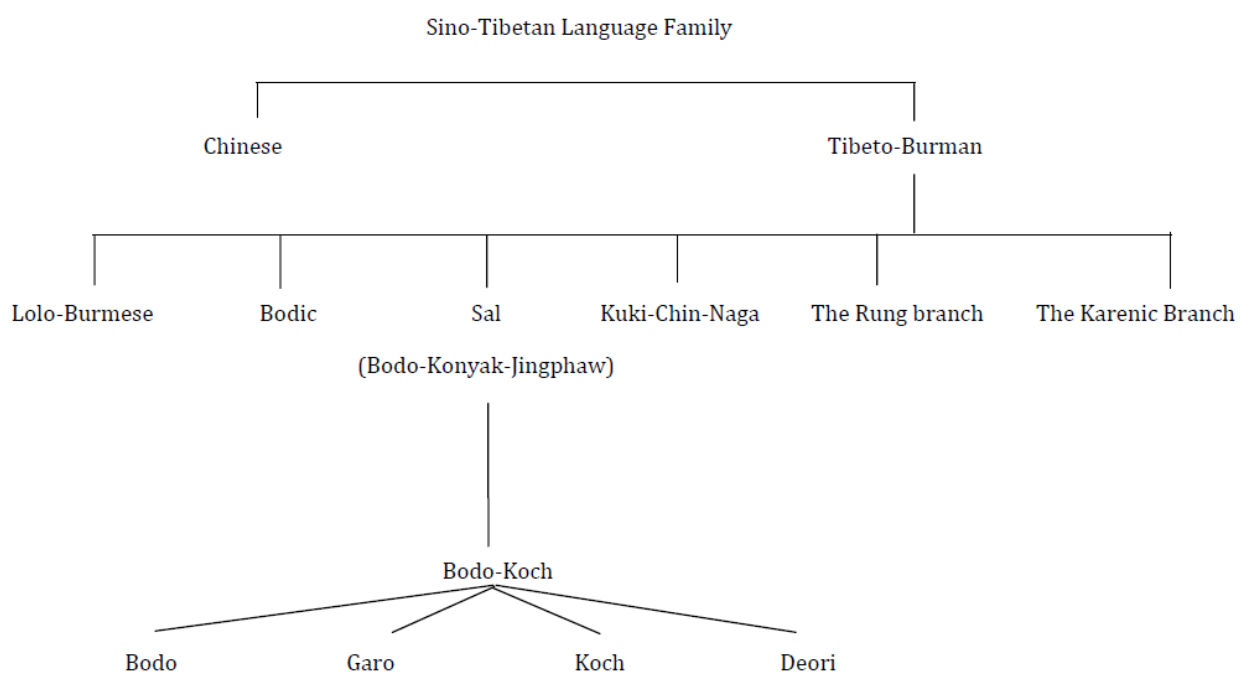

Figure 1: Tibeto-Burman genealogy (based on Thurgood and LaPolla 2003 and Burling 2003)

Figure 1 shows the place of Deori in the Sino-Tibetan language family, based on various observations about Deori in Burling (2003) etc. The Sino-Tibetan language family is comprised of the Chinese and Tibeto-Burman languages, including some two hundred fifty languages 
of East Asia, Southeast Asia and parts of South Asia. The highest concentration of Tibeto-Burman languages in India is found in the north east region which is surrounded by Bhutan, Tibet, Myanmar, and Bangladesh. In Assam there are substantial Tibeto-Burman minorities. Most of the people who belong to the plain tribes are able to speak Assamese, as a second language. Many of the plain tribes who now speak only Assamese still trace their origin to a Tibeto-Burman background. Tibeto-Burman languages may be further divided into six sub-groups: (a) Lolo Burmese (b) Bodic (c) Sal (Bodo-Konyak-Jingpaw) (d) Kuki-Chin-Naga (e) the Rung (f) the Karenic branch

Bodo-Konyak-Jingpaw constitutes a major subgroup of TibetoBurman based primarily in north-eastern India. Amongst these, the Bodo-Koch branch is well established and it has four parts: Bodo, Garo, Koch and Deori. The Bodo branch incorporates several languages such as Boro, Mech, Dimasa, Kachari and Hill Kachari spoken mainly in the valley and the hilly areas to the south. The third branch of Bodo-Koch consists of a single language, Garo, mainly spoken in Western Meghalaya and neighbouring areas of Assam and Bangladesh. The fourth and last branch of Bodo-Koch is 'Deori' or 'Chutia' spoken further east in Assam. Despite its grouping under the Bodo-Koch branch, the exact relationship with other languages is poorly understood. The languages of the Konyak are less well known than the Bodo-Koch group and appear to be more heterogeneous. Referring to Burling's (2003) description of Tibeto-Burman subgroups, we have illustrated these facts in a family tree diagram to give a clear insight into the language family. Thurgood \& LaPolla (2003) also observe that although Deori belongs with the Bodo-Koch languages, the precise point where it joins them is not clear, and they consider it to be deviant (although no reasons are given beyond the absence of mutual incomprehensibility).

Based on assertions such as above, Deori is generally not considered to be distinct from the Bodo-Garo group which is numerically the largest Tibeto-Burman group in Assam. Deori is, therefore, a Tibeto-Burman language spoken mainly in Assam and Arunachal Pradesh, but it constitutes its own subgroup under BodoGaro. Jacquesson (2005) is the first complete grammatical work on the Deori language, describing many phonological processes in Deori as well as a detailed analysis of the language's morpho-syntax.

\subsection{Tonoexodus}

Ratliff (2015) brings together the literature on 'tonoexodus' (Lea 1973) and shows that tone loss is predicted to happen in the context of reinterpretation (Shih 1985, Schadeberg 2009), proximity to toneless 
syllables, and also may involve reanalysis of tone as an accent. It is of course not just a matter of speculation that tone loss can also happen as a result of language contact. Janhunen et al. (2008) note that some Bantu languages have lost their tones as a result of contact with speakers of atonal languages. However, as noted by Clements and Goldsmith (1984), except for two clusters of Bantu which are atonal, all the other neighbouring Bantu languages have lexically distinct tones. The contact explanation seems farfetched for these Bantu groups and also for other languages where tone loss occurs due to languageinternal factors. Ratliff also notes that learnability considerations arising out of a simpler accentual system may be one of the many reasons for the loss of tone. Sometimes radical tone mergers may also prompt tone loss as shown in the study of the Central Vietnamese dialect of Nghe An (Pham 2005).

In the light of all these possible paths to tonoexodus, Deori appears to be a language where the loss of tone could be primarily due to language contact because the neighboring major language, Assamese, is completely atonal. Most Deori speakers in Assam are Assamese-Deori bilinguals. There could also be potential language internal reasons; the loss of sesquisyllabicity ${ }^{1}$ and the presence of toneless syllables could be the language-internal triggers for tonal impoverishment. Tonal mergers seemed to have occurred as a result of loss of the mid tone, the presence of which had been reported by Goswami (1994) etc.

\section{Deori phonemic inventory}

Jacquesson (2005) accounts for 5 oral and 5 nasal vowels in Deori. He mentions some contextual variations of the oral vowels, as shown in (1). ${ }^{2}$

(1)

(a) $[\mathrm{a}]+[\mathrm{y}] \rightarrow[\mathrm{ey}] \sim[\mathrm{e}]$ maimaica $\sim$ meimeica $\sim$ memeca 'slowly'

(b) $[\mathrm{e}]+[\mathrm{y}] \rightarrow[\mathrm{i}] \quad$ meyô $\sim$ miô 'elephant'

(c) $[\mathrm{o}] \rightarrow$ [u] otuy utun 'belly'

(d) $[\mathrm{o}] \rightarrow[\mathrm{u}] \quad$ otû $^{2} \sim \mathrm{utû}^{2} \quad$ 'arm'

Jacquesson (2005) seems convinced that the [o] vowel in Deori comes from the older [a] and has been 'softened' under the Assamese

\footnotetext{
1 This follows Matisoff (1973), who makes the generally accepted claim that Proto Tibeto-Burman was sesquisyllabic (with a 'major' and a 'minor' syllable) and shows that most Tibeto-Burman languages are sesquisyllabic till the present day.

2 As per the tone marking conventions adopted in Jacquesson (2005), high tone is indicated as ' 2 '.
} 
influence. For instance, 'finger' /âshti/ (Brown 1895) is pronounced as [osti] by the younger generation. /borga/ (Brown 1895) 'to boil' is pronounced as [barga]. The tableaux in figure 2 highlight the oral and nasal vowels mentioned in Jacquesson (2005). It seems reasonable to assume that the Deori [a] has undergone rising. The vowels also exhibit a certain amount of chain shift from /a/ $\rightarrow[0],[e] \rightarrow / i /$ and $[0] \rightarrow / \mathrm{u} /$. As the nature and distribution of vowels in Deori is not the primary concern of this paper, we will not discuss these phonological processes in the rest of the paper.

Oral Vowels
\begin{tabular}{|c|c|c|c|c|c|}
\hline & \multicolumn{2}{|c|}{ Front } & \multicolumn{3}{|c|}{ Back } \\
\hline High & $\mathrm{i}$ & & & & $\mathrm{u}$ \\
\hline Mid & & $\mathrm{e}$ & & $\mathrm{o}$ & \\
\hline Low & & & $\mathrm{a}$ & & \\
\hline
\end{tabular}

Table 1: 5 oral vowels in Deori

Nasal Vowels
\begin{tabular}{|l|c|c|c|c|c|}
\hline & Front & \multicolumn{3}{|c|}{ Back } \\
\hline High & $\tilde{\mathrm{i}}$ & & & & $\tilde{\mathrm{u}}$ \\
\hline Mid & & $\tilde{\mathrm{e}}$ & & $\tilde{\mathrm{o}}$ & \\
\hline Low & & & $\tilde{a}$ & & \\
\hline
\end{tabular}

Table 2: 5 nasal vowels in Deori

There are 17 consonants in Deori. They are as follows: / $\mathrm{p} \mathrm{b} \mathrm{t} \mathrm{d} \mathrm{k} \mathrm{m}$ $\mathrm{n} \mathrm{g} \mathrm{t} \int \mathrm{d} \mathrm{w} \mathrm{s} \mathrm{j} \mathrm{h} \mathrm{l} \mathrm{r/.} \mathrm{Except} \mathrm{for} / \mathrm{y}, \mathrm{r}, \mathrm{w} /$, all consonants occur word initially. The velar nasal consonant $/ \mathrm{y} /$ does not occur intervocalically. Only the nasal consonants $/ \mathrm{m} \mathrm{n} \mathrm{g} /$ and the semi vowel /y/ and the approximant $/ \mathrm{r}$ / occur word finally. $/ \mathrm{r} /$ and $/ \mathrm{l} /$ are in complementary distribution. /l/ occurs in the beginning of a word and / $\mathrm{r} /$ occurs elsewhere except the beginning of the word. The phoneme $/ \mathrm{y} /$ is rare in Deori, except in the final syllable where it is deleted in favor of vowel nasalization. [s] is not found at the end of the word. Aspiration in Deori is not phonological as is evident from speakers' use of aspiration in Assamese, as it is often seen that the not-so-fluent speakers are not proficient in producing the aspirated/non-aspirated contrast that exists in that language. The verbal suffix of the present indefinite is /-i/, but in quick pronunciation, it changes depending on the vowel that it follows. It is /i/ after /e, i, u/ and becomes /y/ after /a/ and [o] (Jacquesson 2005).

Goswami (1994) accounts for seven vowel and eighteen consonant phonemes with two semi-vowels. The phonemes are: / i e $\varepsilon$ a a o u, p b t d c j k g m n ṅ l r s z ś x h; y w/. Brown (1895) accounts for 5 vowels in 
Deori - /a e i o u/. Brown discusses the allophonic properties of these vowels and presents the view that the length of these vowels depends a good deal on 'accent'. For consonants, Brown remarks that most of the consonants sound as in English. Deori (2012) reports voiceless palatoalveolar $/ \mathrm{t} \int /$ is used extensively in the language.

\subsection{Deori vowels: Experiment and methodology}

In the first phase of our fieldwork, which initially considered the properties of Deori vowels, we selected minimal pairs from a word list in Jacquesson (2005) for data elicitation and verification. While we chose items from the word list that was available from Jacquesson (2005), it is important to point out that we did not limit ourselves to this list alone. We arrived at the final list after sustained deliberations and discussions with our informants.

The fieldwork was carried out in Naam Deori village of Jorhat district, Assam, a village inhabited only by Deori speakers. Before the production task we elicited each lexical item from the word list in Jacquesson (2005). Auditory judgments were used to ascertain potential tonal differences. During multiple discussion sessions, it emerged that there were quite a few words in the list which could not be confirmed by the native speakers. For instance, in the pair [asija] and [asi ${ }^{2} \mathrm{ja}$ ], the former means 'Khamti' (a tribe) and the latter means 'God of rain' both of which were unanimously rejected by the speakers. Speakers at Naam Deori village insisted that [asi $\left.{ }^{2} y a\right]$ means 'to pray to the god of rain', which is a ritual held every year during the month of April and observed by both the Deori and the Khamti people. But the word [asiya] does not actually mean the Khamti tribe (according to the speakers of Naam Deori village). The monosyllable [ $\mathrm{t} \mathrm{fi}$ which means 'to make' (shown as meaning 'tongue' in Jacquesson 2005) had to be altered. According to the speakers in Naam Deori village, the corresponding word for tongue is [ $\mathrm{t}$ igu]. Moreover there were other words in the list which could not be pronounced in their citation forms. Words like /sin/ 'seven' occurs with numerical classifier 'mu' which together form the derivation /mu-sin/ 'seven' and thereby lose its pairing with /sin/ 'salt'. /tfui/ 'good' and /tfui/ 'confluent' were also taken away from the production study as the native speakers could not confirm the word and its corresponding meaning / $\mathrm{t}$ fui/ 'confluent' (many did not recognize the word).

Apart from the words which were taken out of the production study, the informants gave us words like /garõ/ 'pot' and /garõ/ 'throat' which we considered for our tonal analysis (discussed in section 3). The differences pointed out by our speakers between the 
meanings indicated in the word list and the speaker's knowledge of the language, led to differences between the list in Jacquesson (2005) and the list actually used in our fieldwork. In our discussions we also came across one or two words like /dzi/ which had four homophones. We did not hear any tone in them and so we examined our data with the help of recordings. The recordings also showed that the pitch height of the three words /dzi / 'sweet', /dzi/ 'to tie' and /dzi/ 'torn' varies in the speakers. For the female speaker /dzi/ 'sweet' has the highest pitch contour whereas for the male speaker it is mid. On the other hand, for the male speaker /dzi/ 'torn' and /dzi/ 'to tie' has almost the same pitch height whereas for the female speaker /dzi/ 'torn' is somewhere in the mid and /dzi/ 'tie' shows a rising contour. Since such multiple homophones were almost rare we decided that we could not explore the possibility of more than two tones.

The Jacquesson (2005) list was thus not entirely agreed upon by the informants and it led us to revise the list following their advice. Furthermore, we also changed our priming sentences to suit the altered list and the meaning of the words.

Our sessions with the informants led to the final data set and we finally settled on 18 homophonous sequences, consisting of 5 monosyllables, 9 disyllables and 4 trisyllables, as given in appendix 2 and 3 (the distinction between the sentences in the two appendices is explained in section 3). This was maintained for all the words across the list. The sentences were constructed and printed on a piece of paper. The use of the controlled data for the experiment was carried out to avoid any segmental influence by either the preceding or the following words. It further ensured a uniform intonational environment and also prevented sentence boundary interferences on each of the target words. The sentences were further verified with the informants who participated in the production test. The speakers were asked to utter the sentences at a natural speaking pace and the target word in the "I X said" (the basic Deori word order is SOV) pattern was considered for further investigation. The sentences thus collated were implemented amongst the speakers four times each among a set of five speakers. After each speaker's recording, the sound files were played to the respective speakers for further confirmation and the speakers repeated the sentences, whenever necessary. The age of the speakers ranged between 40-55 years.

After the recording in Naam Deori village in Jorhat district, we planned a second field trip to Bor Deori village in Narayanpur, Lakhimpur District to collect additional data. We did not, however, find sufficient number of speakers for the production test to investigate our intuitions about tone. We therefore decided to use the recordings 
conducted in Naam Deori village of Jorhat district for the analysis of tone as well as vowels, as discussed in section 3.

A list of minimal pairs was also separately collected for a detailed analysis of the phonetic and acoustic properties of vowels in Deori. The list consisted of 54 monosyllabic verbal roots (the list of minimal pairs is in appendix 1). We considered two words (with different meanings) of $\mathrm{CV}$ structure [ $\mathrm{C}$ being the consonant] with 5 speakers and 3 iterations of each word, thus giving $30(2 * 5 * 3)$ samples for each vowel. The recordings were done at a primary school in Narayanpur, Lakhimpur District. The school was devoid of any disturbance and this resulted in a successful recording. An Edirol Roland R-09HR with its inbuilt microphone was used for the recordings. The recordings were digitized at a sampling frequency of $44.1 \mathrm{kHz}$ and $32 \mathrm{bit}$ resolution.

\subsection{Deori vowels: results}

The data thus collected was saved in unique file names indicating the token, speaker, and token number, and these files were manually segmented in Praat. F1 and F2 values were extracted by Praat's autocorrelation method with the help of a script written for the purpose. Tables 3-4 and figures 3-4 show the average F1 and F2 values along with their corresponding durational values. All these values are only relevant to the oral vowels, which have been shown in Mel.

\begin{tabular}{|c|c|c|}
\hline vowel & F1(mel) & F2(mel) \\
\hline $\mathrm{a}$ & 480.99 & 780.37 \\
\hline$\varepsilon$ & 375.61 & 839.58 \\
\hline $\mathrm{i}$ & 317.87 & 848.73 \\
\hline $\mathrm{J}$ & 434.98 & 711.93 \\
\hline $\mathrm{u}$ & 352.81 & 625.32 \\
\hline
\end{tabular}

Table 3: Mel values of all 5 vowels

\begin{tabular}{|c|c|c|}
\hline Vowel & F1(bark) & F2(bark) \\
\hline $\mathrm{a}$ & 7.03 & 11.91 \\
\hline$\varepsilon$ & 5.28 & 12.82 \\
\hline $\mathrm{i}$ & 4.35 & 12.96 \\
\hline $\mathrm{J}$ & 6.26 & 10.81 \\
\hline $\mathrm{u}$ & 4.91 & 9.39 \\
\hline
\end{tabular}

Table 4: Values in bark for all 5 vowels 


\begin{tabular}{|c|c|c|}
\hline Vowel & $\begin{array}{c}\text { Duration } \\
(\mathrm{ms})\end{array}$ & $\begin{array}{c}\text { Standard } \\
\text { Deviation }\end{array}$ \\
\hline $\mathrm{a}$ & 90.53 & 30.11 \\
\hline$\varepsilon$ & 144.66 & 51.45 \\
\hline $\mathrm{i}$ & 155.34 & 39.83 \\
\hline $\mathrm{J}$ & 119.53 & 35.07 \\
\hline $\mathrm{u}$ & 121.05 & 22.2 \\
\hline
\end{tabular}

Table 5: Duration and standard deviation values of all the vowels

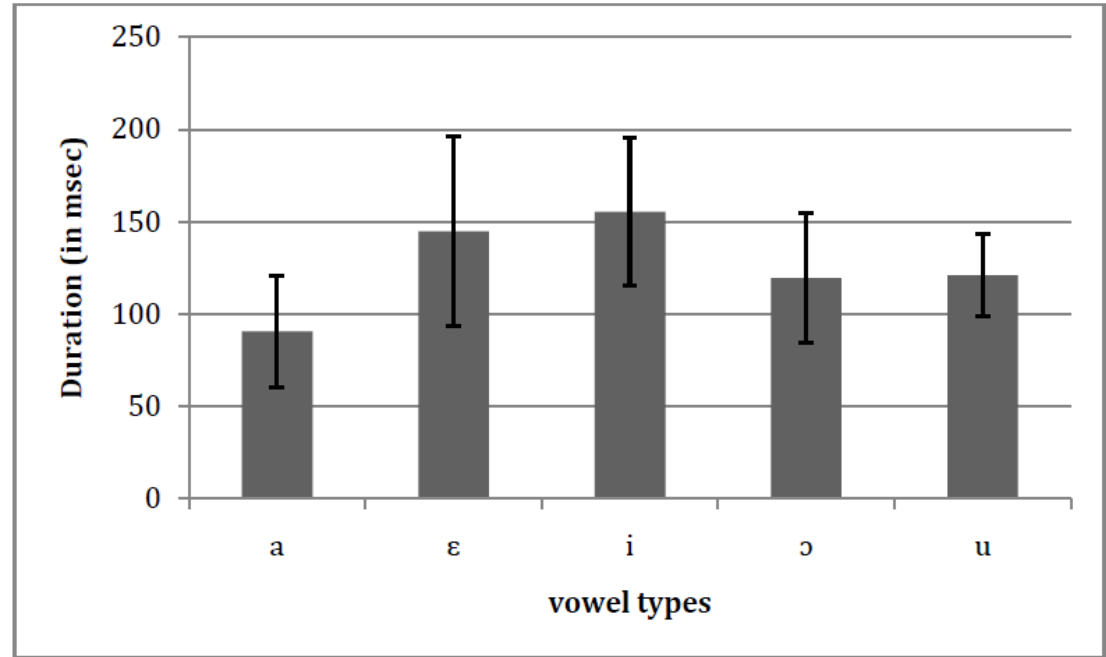

Figure 2: Average duration of Deori vowels with standard deviation as error bars

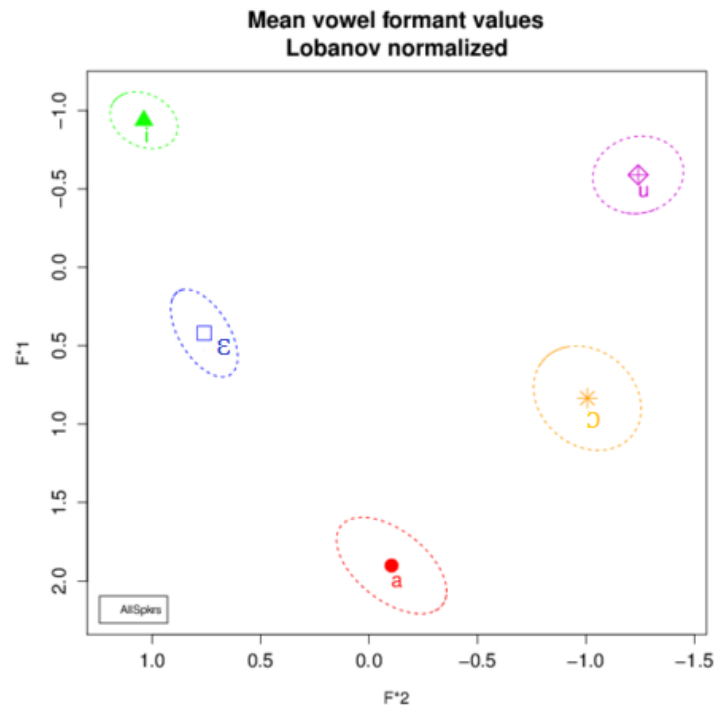

Figure 3: Average Lobanov normalized F1-F2 values for 5 male Deori speakers. 
To verify the vowel inventory in the language the extracted formant values calculated in Mel (in dB) were normalized for speaker variations using the Lobanov normalization method in NORM (Thomas and Kendell 2007). Normalization of the formant frequencies was done to avoid between-speaker variations. In Figure 3, normalized average values of the first and second formants (F1-F2) are represented with one standard deviation ellipses. The results further confirmed the view of Jacquesson (2005) about the existence of five different oral vowels in Deori.

\subsection{Stress in Deori}

Although this is an initial stage of the investigation of stress in Deori, our results point in the direction of a development of an iambic system of stress. We considered twelve bisyllabic words ${ }^{3}$ which were recorded at a moderate speaking rate from three speakers with three repetitions for each word. All words were spoken in a frame sentence "I X said" to avoid lengthening in utterance final position. In order to confirm the statistical significance between the two vowels a one way ANOVA test was conducted with duration as the dependent variable and vowel position as the independent variable and the results show a significant difference between the initial and the final vowel $(\mathrm{p}<0.05)[(\mathrm{F}(1,214)$ $=92.95) p=.003]$. Final vowels were also found to be comparatively longer than the initial vowel. The average values of duration also revealed that duration was considerably longer in the second syllable irrespective of any vowel - V1 was $52.02 \mathrm{msec}$ and V2 was $82.86 \mathrm{msec}$. The results, therefore, showed that there is a significant difference between the two vowels and the second vowel was uniformly longer in the words. The words used in the experiment are shown in (2)

(2) CVCV words used in the experiment on stress
(a) gi.'ku: 'brain'
(b) gu.'tũ: 'nose'
(c) gu.'bõ: 'head'
(d) ke.'pe: 'cotton'
(e) ko.'tu: 'ear-ring'
(f) to.'pe: 'bedsheet'
(g) bo.'se: 'blanket'
(h) pi.'zo: 'raw'

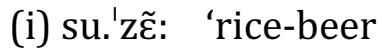
(j) si.'ri: 'night'
(k) di.'sõ: 'pot'
(l) tfi.'nu: 'younger sister
/ brother of wife'

\footnotetext{
3 The actual list has 24 words; we will not discuss the other syllable types here, but suffice it to mention that the iambic theme is maintained in all the syllable types.
} 
The interesting aspect, however, is that this length distinction is not maintained when a word had lexically distinctive tone. In order to understand the relationship between vowel length and tone in Deori, we conducted an ANOVA of the words where duration was set as the dependent variable, with tone being the predictor variable and the results showed no significant effect of tone on duration. The result shows no significant effect for the first syllable of the two tones low and high $(\mathrm{p}>0.05)[(\mathrm{F}(1,358)=.522) p=.471]$. For the second syllable also, the result does not show any significant difference for the two tones $(\mathrm{p}>0.05)[(\mathrm{F}[1,358]=1.056) p=.305]$. We conclude that this shows that there were no durational differences between the syllables insofar as tonal distinction was concerned. Thus the syllables were not different from each other in terms of duration.

Furthermore, we also compared the durational differences between V1 and V2 for (potentially) low tone and V1 and V2 for (potentially) high tone in order to examine the differences between the two vowels within a word. The words in the experiment had the following vowel sequences: /a_u/, /i_u/, /i_a/, /i_i/, /u_u/, /a_o/. Considering vowel position as the independent variable and durational values to be the dependant variable, a one way ANOVA test was conducted. The result showed no significant difference between the vowels V1 and V2 both for low tone $(\mathrm{p}>0.05)[(\mathrm{F}[1,358]=.025) p=.875)$ and for vowels V1 and $\mathrm{V} 2$ for high tone $(\mathrm{p}>0.05)[(\mathrm{F}[1,358]=.346) p=.557)$. The average durational values for V1 and V2 for low tone were $67.74 \mathrm{msec}$ and $67.20 \mathrm{msec}$ respectively and for V1 and V2 for high tone were 65.57 msec and $63.87 \mathrm{msec}$ respectively. These statistical results indicate that duration has no effect on tonal realization in Deori and also that the durational differences between the two vowels in a disyllable are next to negligible.

The results seem to point towards a trade-off between the development of an iambic stress pattern and loss of tone. Following Matisoff (1973) and Matisoff (1989), it is a generally accepted claim that Proto Tibeto-Burman is sesquisyllabic with a 'major' and a 'minor' syllable and it has been shown that most Tibeto-Burman languages are sesquisyllabic till the present day. Our consideration of the Deori lexicon showed an absence of sesquisyllabicity: the quality of the initial vowel is unrestricted across words and it did not resemble minor syllables in any particular way. Our preliminary results provide evidence for the development of an iambic stress system in the language with the second vowel being systematically longer. From the experiments conducted for potentially tonal and non-tonal words it is apparent that for non-tonal words, duration of the second syllable is longer and more prominent (irrespective of vowel quality). The 
lengthening of the second syllable clearly follows the Iambic-Trochaic Law (Hayes 1995:80) where it is hypothesized that there is lengthening of the stressed syllable in the iambic system rather than in the trochaic system. The development of this stress system was probably prompted by two language internal factors: loss of sesquisyllabicity and loss of tone, although much cannot be said about the particular order of the historical loss of these two phonological properties.

\section{Deori Tones}

While Brown (1895) alludes to the presence of contrastive 'intonation' and nasalization in an effort to characterize what would now be considered a lexical tonal contrast, Goswami (1994) describes the presence of three tones in Deori. In contrast, Jacquesson (2005) provides a list of 34 pairs of words that are tonally distinct in terms of two tones, 'High' and 'Low', while maintaining the view that tonal distinctions are moribund in Deori.

Tone in other genetically related Tibeto-Burman languages such as Boro, Dimasa and Tiwa has been shown to have fixed acoustic properties related to their tonal levels. Boro has been shown to have falling and rising (Sarmah 2004, Burling 1959). Dimasa has high rising, mid level and low falling tones (Sarmah and Wiltshire, 2010), and Tiwa and Rabha have falling, rising and mid (Joseph and Burling 2001, Sarmah 2009). Therefore, we can surmise that the Tibeto-Burman languages of the Bodo-Garo subgroup have a phonetically falling tone for a Low tone and a rising tone for a High tone. Hyman (2007) notes that tone specifications can be extremely 'dense' with a tone specified for each and every TBU. On the other hand, tone specifications can also be 'sparse' with various prosodic or positional restrictions on their occurrences. While there is no doubt that tone is not densely specified in Deori, the question remains whether tone really is specified in otherwise homophonous pairs, which is a strong indicator of a tone language if large numbers of such pairs are present.

The question we sought to answer in Deori was regarding the nature of tonal properties, that is, first of all, if there still are any phonetically and phonologically viable lexical tone contrasts, and if there are, in which ways lexical tone would manifest in the language. Our investigation of the tonal properties of Deori led us to understand the complex nature of tonal distinctions in the language. Detecting the true nature of tonal distinctiveness seemed difficult in the absence of clear, impressionistically available tonal distinctiveness. The acoustic properties of tone in Deori did not adhere too much to the known facts of tonal properties of Tibeto-Burman languages. In the history of the 
analysis of the language, there have been many observations about tone. The first extant one is that of Goswami (1984) who proposes three tones in Deori, as in table 6.

\begin{tabular}{|c|c|c|}
\hline Tone type & Word & Gloss \\
\hline even tone & ni & to drink \\
\hline high tone & ní & to sing \\
\hline low tone & nì & to hold \\
\hline
\end{tabular}

Table 6: Three tones in Deori as posited by Goswami (1984) 4

Jacquesson (2005) remarks that although tonal opposition is now more or less moribund in Deori, it certainly was present at a certain point of time in the language and it may be difficult to locate that stage chronologically. The loss of tonal oppositions can be seen in the speech of the majority of informants nowadays. Tones are not salient in everyday communication, and clear oppositions only become apparent in elicitation situations (Jacquesson 2005). Jacquesson's book has 34 homophonous words, out of which 21 are monosyllables, 12 disyllables and 2 trisyllabic words, and this was the basis of the list that we used for our experimental investigation into the extent of tone loss (the nature of the list is discussed in section 2.1). The words [giga-], /kiga-/ and /nija-/ were considered trisyllabic when a suffix was added after each three words, as mentioned in Jacquesson, (2005, 349-392). Our revised list is given in appendix 2 . It has 18 homophonous sequences, out of which 5 were monosyllables, 9 disyllables and 4 were trisyllabic. The monosyllabic words are of CV syllable type, disyllabic words are of VCV, CVCV syllable types and trisyllabic words are of CVCVCV, VCVCV syllable types. However, in this paper we have concentrated only on the tonal properties of monosyllabic and disyllabic words.

\subsection{Deori Tones: the Experiment}

The list of eighteen word pairs that might contrast in pitch height was prepared for the production study to investigate the tonal inventory of the language (if any). The set of words is shown in table 7 , where high tone is indicated by a 2 superscript.

${ }^{4}$ In our elicitation task, these three tonal contrasts were not found. There was no difference between nì 'to hold' and ni 'to drink'. 


\begin{tabular}{|c|c|c|c|c|c|}
\hline Deori & Gloss & Deori & Gloss & Deori & Gloss \\
\hline $\mathrm{t} \int \mathrm{i}^{2}$ & blood & tiri $^{2}$ & banana & nini $^{2}$ & holding \\
\hline $\mathrm{t} \int \mathrm{i}$ & to make & tiri & $\begin{array}{l}\text { hang from a } \\
\text { tree }\end{array}$ & nini & drinking \\
\hline $\mathrm{t} \int \mathrm{u}^{2}$ & to talk & kiri $^{2}$ & poor & tfitu & old \\
\hline $\mathrm{t} \int \mathrm{u}$ & pig & kiri & $\begin{array}{l}\text { to furnish with } \\
\text { heddles }\end{array}$ & tfitu & rope \\
\hline $\mathrm{ko}^{2}$ & pluck & $\mathrm{uzu}^{2}$ & bamboo tube & kigari $^{2}$ & peel \\
\hline ko & come & uzu & navel & kigari & hang \\
\hline $\mathrm{li}^{2}$ & heavy & $\mathrm{aku}^{2}$ & upland & kusiri $^{2}$ & whistle \\
\hline li & necklace & aku & ear & kusiri & medicine \\
\hline $\mathrm{tu}^{2}$ & deep & bari $^{2}$ & carry on back & gigari $^{2}$ & $\begin{array}{l}\text { build house, } \\
\text { platform }\end{array}$ \\
\hline tu & oil & bari & garden & gigari & $\begin{array}{l}\text { sing, cry } \\
\text { (cock) }\end{array}$ \\
\hline $\mathrm{t} / \mathrm{iya}^{2}$ & $\begin{array}{l}\text { wife of } \\
\text { younger } \\
\text { brother }\end{array}$ & garo $^{2}$ & throat & nijani $^{2}$ & $\begin{array}{l}\text { rescue from } \\
\text { water }\end{array}$ \\
\hline $\mathrm{t}$ fiya & fish & garo & pot & nijani & cooking \\
\hline
\end{tabular}

Table 7: Tone list used for the production study

The methodology employed to obtain potential lexical tone contrasts was to first elicit different sentences with the words properly embedded in a sentence with their associated meanings. This method may also be called priming. The sentences were constructed and printed on a piece of paper. The sentences which were used as priming in order to maintain the tonal contrast between the words may be found in appendix 2 .

Five speakers were then asked to utter the word in sentence medial position at a natural speaking pace, in a sentence frame 'I X say' where $\mathrm{X}$ is the target word, across the list. The target word which could potentially bear the tonal contrast thus appeared in a sentence-medial position in a carrier sentence. The target words and the carrier sentences may be found in appendix 3 .

The carrier sentence seen in appendix 3 was used across all the word pairs. As the speakers were well-versed in Assamese and since the Deori speakers have adopted Assamese orthography for the purpose of written Deori, all the sentences were written in the Assamese script. The sentences were thus implemented amongst the speakers four times each among a set of 5 speakers.

\subsection{Deori Tones: Data Processing and Analysis}

After collection of the speech data, the recordings were processed and analyzed using Praat (Boersma \& Weenink 2010). Each iteration of the target word within each sentence was segmented based on information in the waveform and in the spectrogram. The sound files were annotated in a Praat text grid. A normalized f0 script was used to get the measurements such as duration, intensity, f0 mean, f0 vowel mid, maximum pitch, minimum pitch, pitch range, standard deviation, non- 
normalized values each at $10 \%$ interval of time, and $\mathrm{z}$ score values also at $10 \%$ interval of time. The f0 vowel mid values were further extracted in a different excel file and used to see any differences between a high and low tone and any fo difference between the vowels in disyllables and trisyllable (within the same word).

The goal of the $\mathrm{f} 0$ analysis was to determine whether there was any presence of lexical tone and, if so, the way in which the fo curves indicate the distribution of the lexically distinct tones. The following few figures display mean f0 curves which are averaged across all the four repetitions of the 5 speakers. Since it is impossible to show all of them efficiently, only the averaged curves are displayed. We conducted statistical analyses to ascertain the reliability of the differences that we systematically observe in the graphs shown below. Segment boundaries of the tonal domains were manually labeled within Praat. f0 information was also obtained in Praat. Each data point was transformed into z-score via Lobanov's (1971) z-score metric (z= (F$\mu) / \sigma)$. The normalized f0 value (z) was calculated as the difference between the raw f0 in Hertz (F) and the mean f0 of each subject in Hertz $(\mu)$, divided by the standard deviation of the overall f0 of the same speaker $(\sigma)$. The diagrams of the words selected for this experiment show that the pairs of homophones indeed have different levels of f0. The impressionistic observation of the existence of the Low versus High opposition was further confirmed by results in a Mixed Models Analysis. There was a significant effect of lexical tone on the mid fo (Mel). Further, we also conducted a one way ANOVA to confirm the significance of the difference between the fo of the vowels in the high and low tones. The figures below thus show the normalized pitch contours of tonal domains. For the purposes of visual observation we first present the monosyllables and then the disyllables.

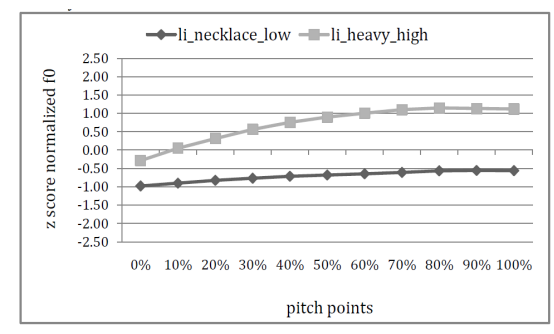

Figure 4: Normalized pitch contours for [li], (n=20\{5 speakers*4 iterations each $\})$ 


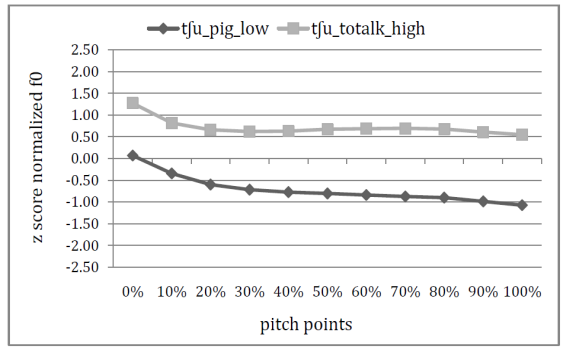

Figure 5: Normalized pitch contours for $[\mathrm{t} f \mathrm{u}],(\mathrm{n}=20\{5$ speakers $* 4$ iterations each $\})$

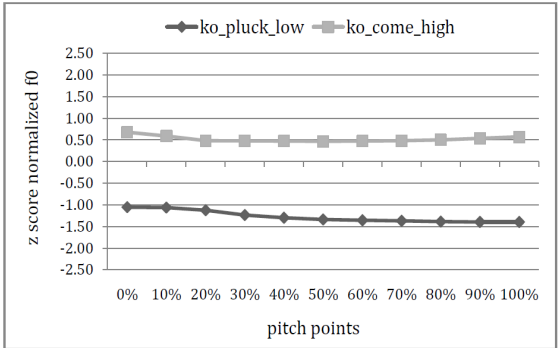

Figure 6: Normalized pitch contours for [ko], $\left(\mathrm{n}=20\left\{5\right.\right.$ speakers ${ }^{*} 4$ iterations each $\left.\}\right)$

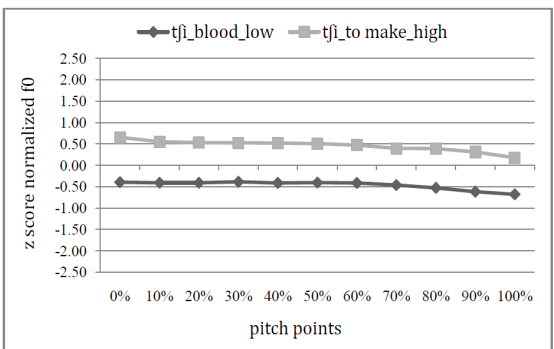

Figure 7: Normalized pitch contours for $[\mathrm{t} f \mathrm{i}],(\mathrm{n}=20\{5$ speakers* 4 iterations each $\})$

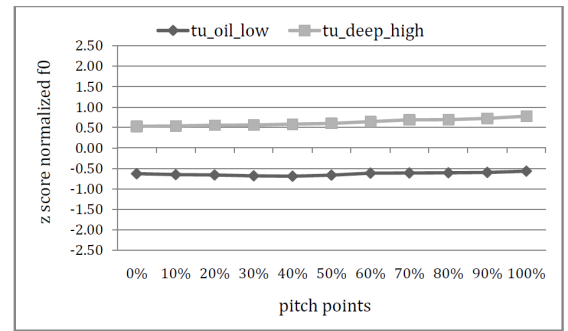

Figure 8: Normalized pitch contours for [tu], $(\mathrm{n}=20\{5$ speakers* 4 iterations each $\})$ 


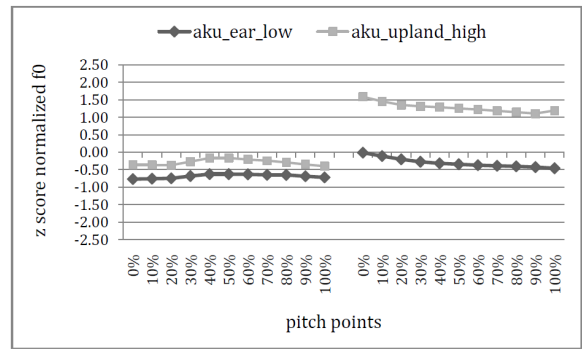

Figure 9: Normalized pitch contours for [aku], $(n=20\{5$ speakers* 4 iterations each $\})$

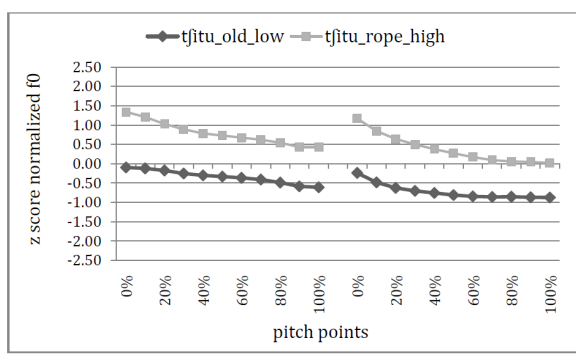

Figure 10: Normalized pitch contours for [ $\left.\mathrm{t} \int \mathrm{itu}\right],\left(\mathrm{n}=20\left\{5\right.\right.$ speakers $^{*} 4$ iterations each $\left.\}\right)$

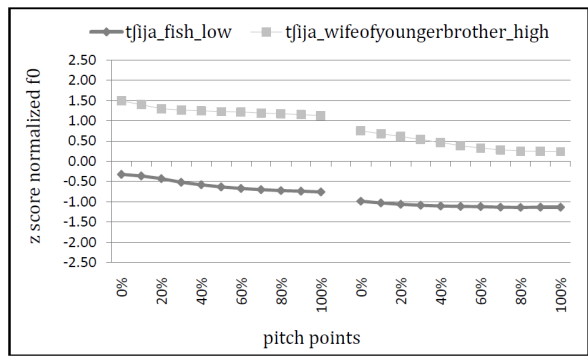

Figure 11: Normalized pitch contours for [t $\mathrm{t} \mathrm{ija}],(\mathrm{n}=20\{5$ speakers $* 4$ iterations each $\})$

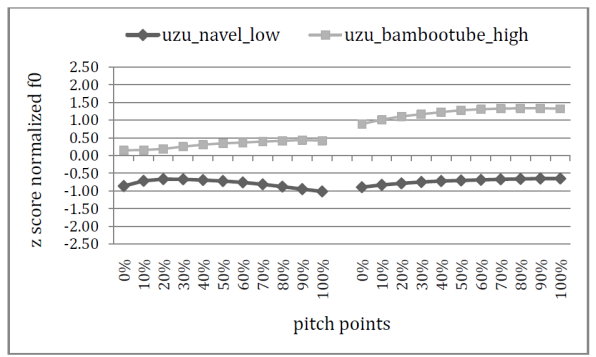

Figure 12: Normalized pitch contours for [uzu], (n=20\{5 speakers*4 iterations each $\})$ 


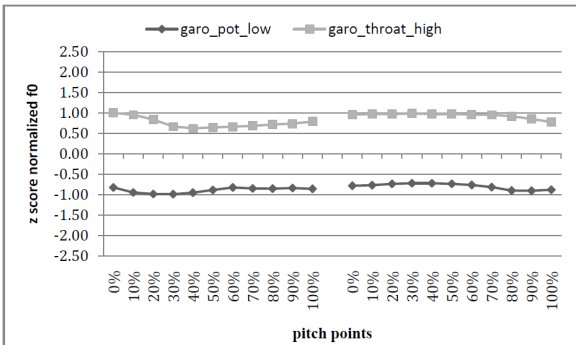

Figure 13: Normalized pitch contours for [garo], ( $n=20\{5$ speakers* 4 iterations each $\})$

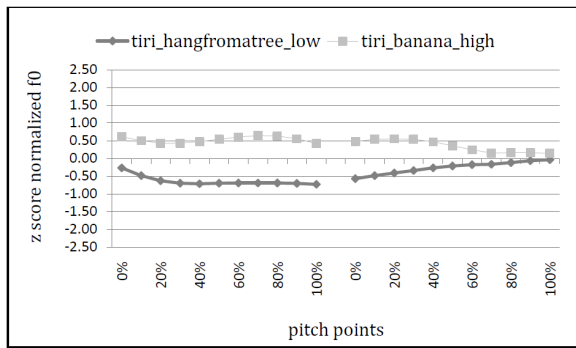

Figure 14: Normalized pitch contours for [tiri], $(\mathrm{n}=20\{5$ speakers* 4 iterations each $\})$

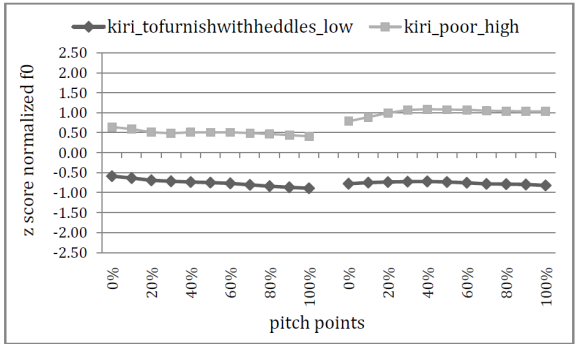

Figure 15: Normalized pitch contours for [kiri], $(n=20\{5$ speakers* 4 iterations each $\})$

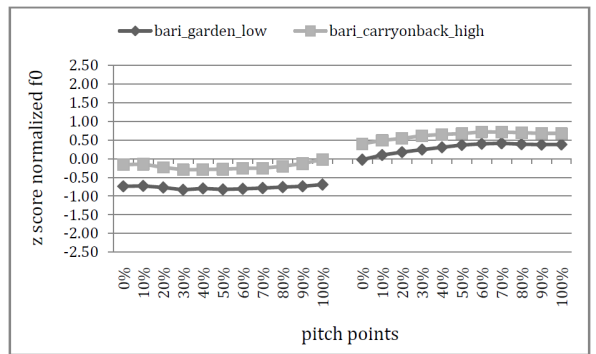

Figure 16: Normalized pitch contours for [bari], ( $\mathrm{n}=20\{5$ speakers* 4 iterations each $\})$ 


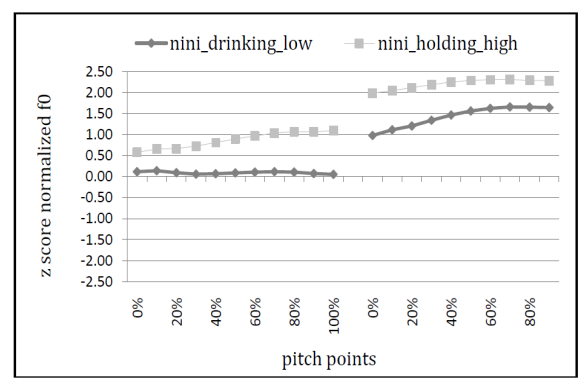

Figure 17: Normalized pitch contours for [nini], (n=20\{5 speakers* 4 iterations each $\})$

As the figures above show, there was always a difference in pitch between the two words in the pairs of words chosen for this study. We conducted a one way ANOVA using the Subject as independent variable and the fundamental frequency of each individual as dependent variable and the results showed clear fo differences indicating a separation of low vs. high tone in Deori. The first comparison made was between the $\mathrm{z}$ score values of the monosyllabic high tone with the low tone. For monosyllables we got an overall significant result for all the $\mathrm{z}$ score f0 points between high and low tones. $(\mathrm{p}<0.05)[(\mathrm{F}[1,98]=$ 294.8), $p=.000]$. To further consolidate our results, we used a linear mixed effects model - lme4 (Bates, Maechler \& Bolker 2012) with likelihood ratio tests and it showed a significant difference between a model with tone as a predictor and a null model; $\mathrm{p}<0.05$. Tone with two levels, high and low was the fixed effect. Intercepts for Subjects and Iterations were the random effects. As figure 18 shows, the two sets of monosyllables are widely divided insofar as mean f0 is considered.

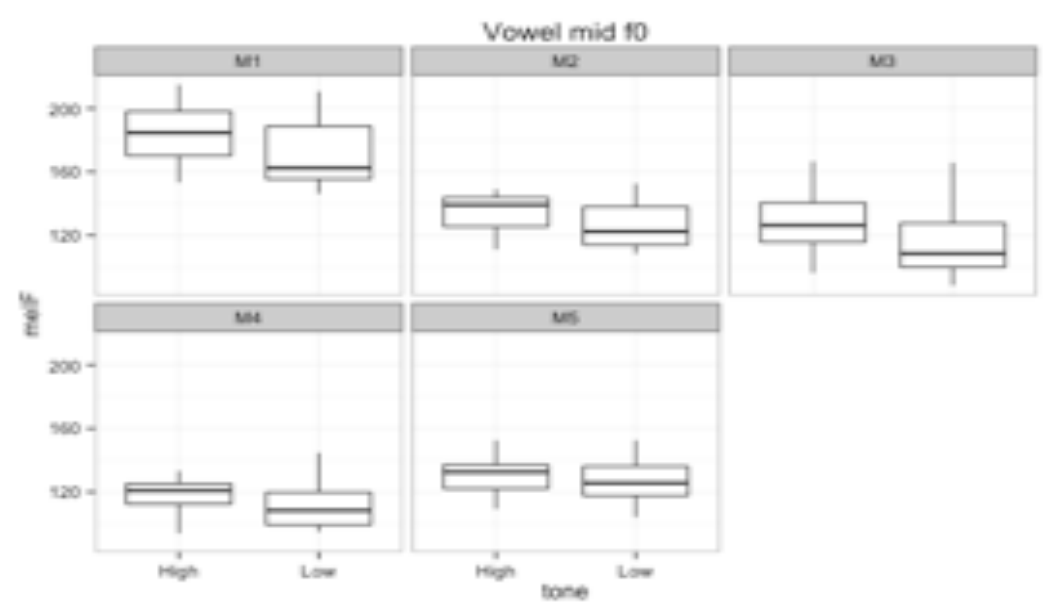

Figure 18: Speaker-wise distribution of the f0 values of the low tone and high tone vowels in the mid-vowel position (in monosyllables) 
Having established that there are indeed two lexical tones in Deori from the handful of words that we investigated, we tried to probe if we can establish the Tone Bearing Unit in Deori. A statistically significant level of $(\mathrm{p}=0.05)$, and 95\% confidence interval of the difference was used to determine the presence of tone at a particular part of the word vis a vis the other parts of the word. This test was mainly conducted for the disyllabic words with both tones, high and low. To discern the relation of the initial vowel and the final vowel of both the syllables, we proceeded in the following way: we took into consideration the average $\mathrm{z}$ score f0 values. At first we tried to estimate the overall effect of all the $\mathrm{z}$ score points for both the vowels and for both the tones. With the vowel position as the factor and the average $\mathrm{z}$ score f0 values as the dependent variable, the results showed significant effects for both the vowels in both the tones when the two tones were compared. We compared the first vowel of the high tone with the first vowel of low tone words. The first vowel of the high tone was significantly different from the first vowel of the low tone: $(\mathrm{p}<0.05)[(\mathrm{F}[1,138]=261.46) p=$ $.000]$. We compared the f0 values of the low tone and high tone words in the second syllable. Even this test showed that the z score values of the low tone words and the high tone words are significantly different from each other: $(\mathrm{p}<0.05)[(\mathrm{F}[1,138]=353.34) p=.000]$.

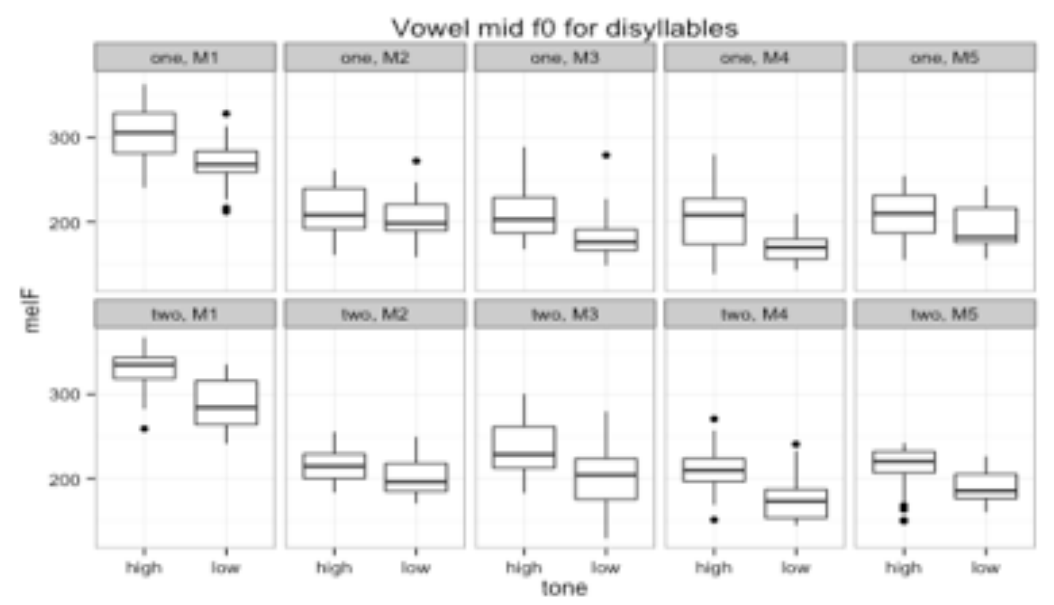

Figure 19: Mid vowel positions of the two vowels in disyllables. One indicates the vowel of the first syllable; two indicates the vowel of the second syllable. The differences are shown for individual speakers 


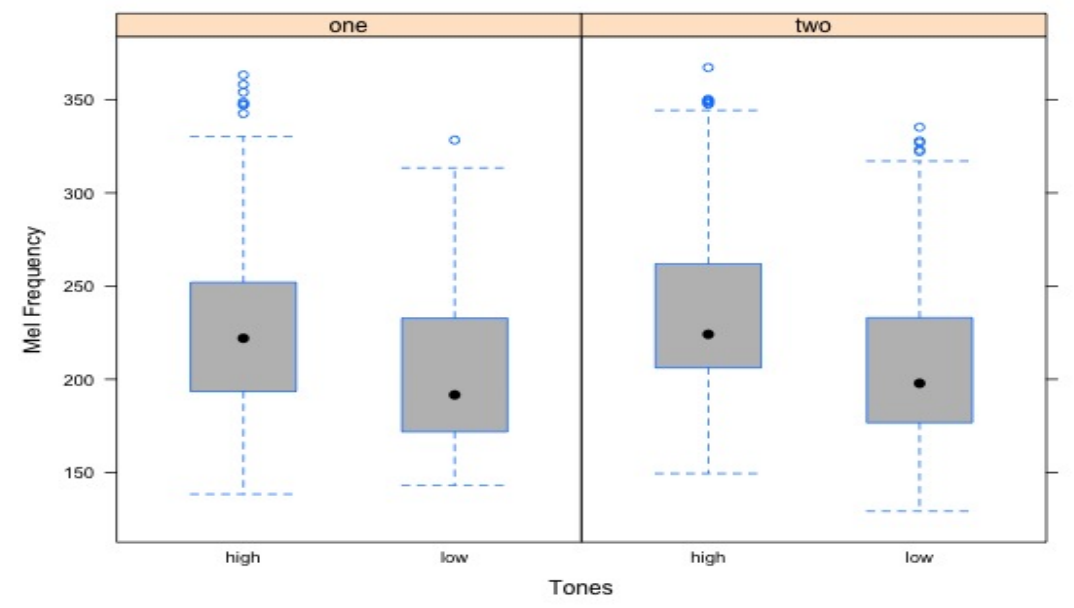

Figure 20: Mid vowel positions of the two vowels in disyllables. One indicates the vowel of the first syllable; two indicates the vowel of the second syllable. Diagram shows the overall differences across speakers.
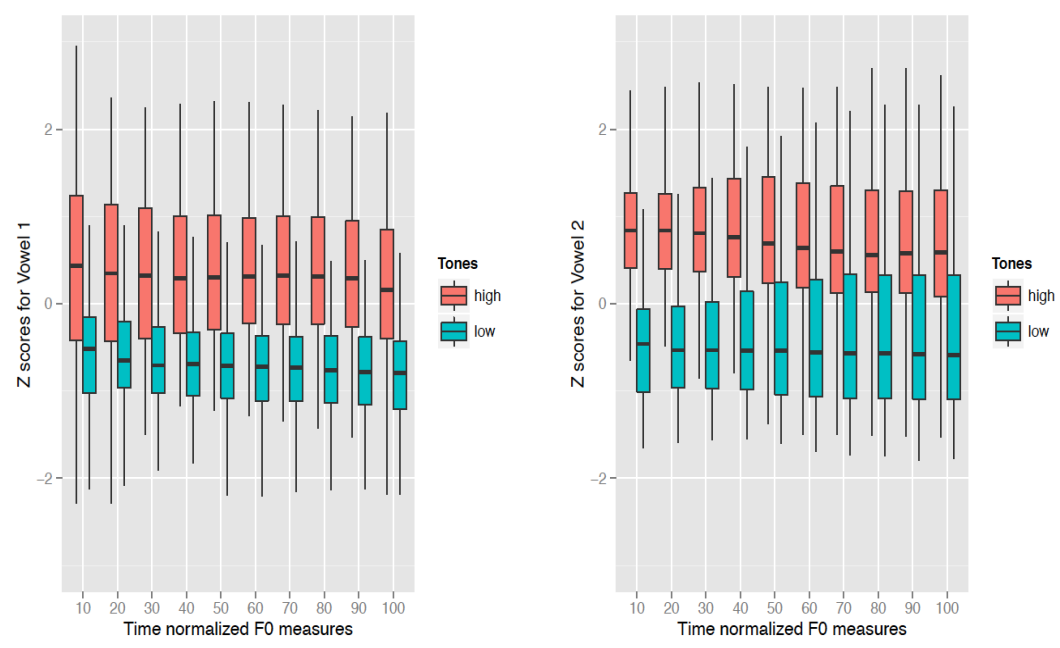

Figure 21: F0 normalized z score distribution in the vowels of the high and low tone words.

As can be seen in Figures 18, 19, 20 and 21, the results did not point towards one unambiguous position for the TBU in Deori. Deori tones do not seem to be assigned to each and every syllable. It is congruent with our results which find the same tone (low and high tone) on both the syllables of each word. While it confirms our hypothesis that tones will be assigned per word in Deori, just like other Tibeto-Burman languages in the vicinity (Bodo, Dimasa etc.), the results did not lead us to a robust indicator of tonal alignment in Deori. The tests conducted so far did not show any convincing result suggesting whether it was the rightmost or the leftmost edge of the word which to which the lexical tone is aligned. Our aim to acoustically verify the position of the TBU became 
prohibitively difficult in the face of results which showed both the vowels of both the tones were equally different. The results also showed that both the vowels are significantly different in the two sets of words only in the high tone and not in the presence of the low tone. In the case of the low tone words, when the $\mathrm{z}$ score points from 10 $100 \%$ were considered, the results showed there was no significant difference between the midpoints of the vowels of the two syllables, as $(\mathrm{p}>0.05)[(\mathrm{F}[1,138]=.102) p=.750]$. On the other hand, the results were different for high tone words. When an overall comparison of $\mathrm{z}$ score points of vowel 1 (from 10-100\%) was compared to the 10 $100 \%$ of vowel 2 for the high tone counterparts, the results were significant: $(\mathrm{p}<0.05)[(\mathrm{F}[1,138]=5.52) \mathrm{p}=.020]$.

The Deori tone contour for a majority of the words showed that there is a rise in the second syllable, especially in the high tone. If we take a simple average of the mid points of the high tone and the low tone words as an index of the maximal height of the high tone then it shows that on an average the mid points in the second syllable is about 8 Hertz higher than the first. The average f0 of the second vowel on an average is almost level or about a Hertz lower than the vowel of the first syllable in low tones.

(3) Average vowel mid points in disyllables

$\begin{array}{ccc}\text { Low } & \text { V1 } & \text { V2 } \\ & 142.69 & 141.43 \\ \text { High } & \text { V1 } & \text { V2 } \\ & 162.43 & 170.05\end{array}$

The contours in Figures 9-17 showed that the high tone words bore a higher $\mathrm{f} 0$ in the second syllable. Figure 22 shows well-differentiated f0 of the second vowel in $10-100 \%$ of the contour. 


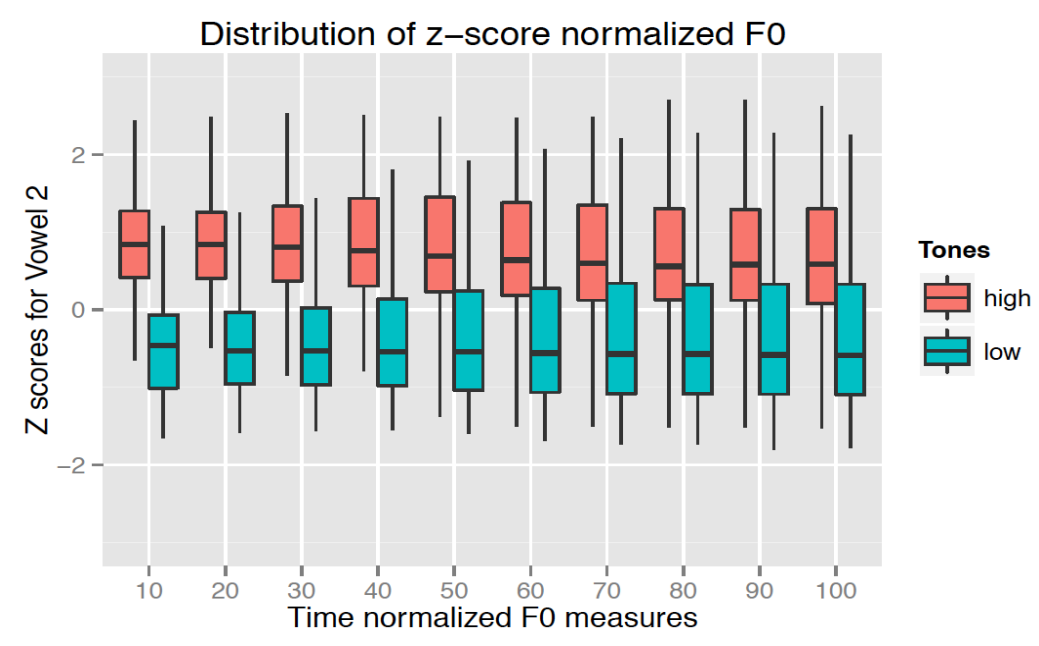

Figure 22: Box plots showing well-differentiated f0 of the second vowel $10-100 \%$ of the contour.

These results may cursorily point in the direction that the vowel of the second syllable is the site for tone docking in Deori. However, we conclude that the syllable is not the Tone Bearing Unit in the traditional sense, and there is no alignment and spreading of the tone to the right edge. Thus, there is strong evidence that tone is distinctive in the entire word in Deori but there may be some remnant alignment on the second syllable like the other languages in the vicinity, e.g, Bodo, which shows more robust results (Sarmah 2001).

Furthermore, we conducted another ANOVA taking into account the final thirty percent of the initial vowel and the first thirty percent of the final vowel, the result showed a significant effect in terms of overall variation for the high tone words for the respective average $\mathrm{z}$ score points $(\mathrm{p}<0.05)[(\mathrm{F}[1,40]=11.24) p=.002]$. The same test was also conducted for the low tone words. With the vowel position as the factor and the average $\mathrm{z}$ score f0 values as the dependent variable, the result showed a significant effect in terms of overall variation for the low tone words only for the last thirty percent and the initial thirty percent of the both the vowels $(\mathrm{p}>0.05)[(\mathrm{F}[1,40]=3.25) p=.079]$. However, when we considered the final twenty percent of the initial vowel and the initial twenty percent of the final vowel, and again the final ten percent of the final vowel and the initial ten percent of the final vowel the result showed no significant effect in terms of overall variation $(p<0.05)$. We can interpret this as some amount of consonantal influence on the vowel of the second syllable but because of the fo lowering for low tones it does not show up as statistically significant. 


\subsection{Conclusion}

In this paper we have contributed to the understanding of Deori as a language which must have had robust tonal distinctions historically, but where the presence of tone has been unclear, and which is in contact with toneless languages. We have shown that Deori still has some tonal properties, marginal as they may be, which still contribute to maintaining contrast in the small sample size taken up for study in this paper. Whether the overall difference in pitch seen in this production study is also valid for perception remains to be examined. How pitch and other laryngeal features are relevant for higher levels of prosodic organization needs to be studied for a better description and analysis of Deori. Tonoexodus or tone loss in Deori is, nonetheless, reflected in the disyllable being the site of the tone target where the TBU is the entire disyllable. The loss of tonal contrast is also related to the development of an iambic system of stress. This is highlighted by our experimental results where it is observed that if there is no lexically distinctive tone, then the iambic stress pattern shows robust second syllable lengthening. However, if lexical tone distinctions are present then the vowel in the second syllable is not longer in duration. It may be conjectured that Deori is in an intermediate stage where tonoexodus is not complete, but the language is on its path towards emerging as a stress-accent system without tone.

\section{Comments invited}

PiHPh relies on post-publication review of the papers that it publishes. If you have any comments on this piece, please add them to its comments site. You are encouraged to consult this site after reading the paper, as there may be comments from other readers there, and replies from the author. This paper's site is here:

https://doi.org/10.2218/pihph.2.2017.1906

\section{Acknowledgements}

The authors would like to thank the Indian Council of Social Science Research (ICSSR) for their grant towards the research project 'A Phonological and Sociolinguistic Study of Variation'. 


\section{Author contact details}

Shakuntala Mahanta, Prarthana Acharyya

Department of Humanities and Social Sciences

Indian Institute of Technology

North Guwahati, Assam

Pin-781039, India

smahanta@iitg.ernet.in, a.prarthana@iitg.ernet.in

Indranil Dutta

Department of Computational Linguistics

English and Foreign Languages University

Hyderabad, Andhra Pradesh

Pin-500007, India

indranil@efluuniversity.ac.in

\section{Appendix 1}

\begin{tabular}{|c|c|c|c|c|c|c|c|c|c|c|c|}
\hline Deori & Gloss & Deori & Gloss & Deori & Gloss & Deori & Gloss & Deori & Gloss & Deori & Gloss \\
\hline ba- & carry & t $\int a-$ & bad & ha- & eat & ka- & bitter & ka- & climb & la- & take \\
\hline sa- & ill & $d_{3} a-$ & sharp & $d_{3} a_{-}$ & throw & bo- & beat & 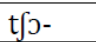 & contain & jo- & cut \\
\hline ko- & come & ko- & pluck & lo- & hard & SJ- & twin & $\mathrm{t} \int \varepsilon$ & milk & ge- & hard \\
\hline $\mathrm{j} \varepsilon-$ & bite & $\mathrm{k} \varepsilon-$ & go & $l \varepsilon-$ & give & le- & grind & $\mathrm{m} \varepsilon-$ & fat & $s \varepsilon-$ & spread \\
\hline te- & attach & $\mathrm{d}_{3} \varepsilon^{-}$ & birth & bi- & peel & $\mathrm{t} \int \mathrm{i}-$ & die & gi- & plant & hi- & plough \\
\hline li- & flow & li- & cut & li- & heavy & pi- & break & si- & clean & ti- & hang \\
\hline$d_{3} i_{-}$ & buy & $d_{3} i^{-}$ & sweet & t $\int u-$ & good & du- & perch & hu- & $\begin{array}{l}\text { clear } \\
\text { weed }\end{array}$ & ku- & fall \\
\hline $\mathrm{ku}-$ & shoot & lu- & pour & lu2- & long & pu- & draw & su- & sting & su- & bark \\
\hline su- & wash & tu & $\begin{array}{l}\text { push } \\
\text { down }\end{array}$ & tu- & deep & $\mathrm{u}-$ & $\operatorname{mix}$ & $d_{3} u-$ & call & $d_{3} i^{-}$ & water \\
\hline
\end{tabular}

\section{Appendix 2}

\section{Monosyllables}

1. $\mathrm{t}$ u (pig)

bari.ho t fu hidu.ri

garden.LOC ${ }^{5}$ pig enter.PROG 6

'Pig is entering the garden'.

${ }^{5}$ Locative marker

6Progressive marker 
$\mathrm{t} \int \mathrm{u}$ (to talk)

t $\int u$ itfa.zu.be.na kobe

talk speak.call.IMP ${ }^{7}$.DEF ${ }^{8}$ come.IMP

'Come, lets talk'.

2. $\mathrm{t} \int \mathrm{i}$ (blood)

t $\int \mathrm{i}$ sangira

blood red

'Blood is red'.

$\mathrm{t} \int \mathrm{i}$ (to make)

bou.t $\int$ on mitur $\mathrm{t} \int \mathrm{i}$

they.INSTR ${ }^{9}$ relationship make

'Let's make relationship with them'.

3. kJ (come)

no dipur.mai kJ

you tomorrow.DAT ${ }^{10}$ come

'You come tomorrow'.

ko (pluck)

buzi zubura ko.ri

sister-in-law vegetables pluck.PROG ${ }^{11}$

'Sister-in-law is plucking vegetables'.

4. li (necklace)

a.jo li.ja iga.i

I.GEN $^{12}$ necklace.DAT beautiful.HAB ${ }^{13}$

'My necklace is beautiful'.

li (heavy)

li atirin

heavy stone

'Heavy stone'.

7Imperative marker

${ }^{8}$ Definite marker

${ }^{9}$ Instrumental marker

${ }^{10}$ Dative marker

11 Progressive marker

${ }^{12}$ Genitive marker

${ }^{13}$ Habitual marker 
5. tu (oil)

ã kin.hว tu budu.ri

I hair.LOC oil massage.PROG

'I am applying oil on my hair'.

tu (deep)

tu zi.mai da.ke

deep water.DAT NEG ${ }^{14}$.go

'Don't go to deep water'.

\section{Disyllables}

1. aku (ear)

zou aku.tऽon kina.i

we ear.INST hear.HABI

'We hear with our ears'.

aku (upland)

lakani ja.wa aku

DET soil.CL ${ }^{15}$ upland

'That is upland'.

2. bari (garden)

bari.ho iba bani

garden.LOC flower bloom

'Flower blooms in the garden'.

bari (to carry on back)

ba mousa.na ba.ri

he child.ACc ${ }^{16}$ carry on back.PROG

'He is carrying the child on his back'.

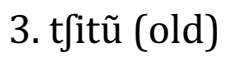

la tfitu jorubj

DET old book

'This is an old book'.

\footnotetext{
14Negation

15 Classifier

${ }^{16}$ Accusative marker
} 
tfitũ (rope)

tfitu.na laha.be

rope.CLbring.IMP

'Bring the rope'.

4. kiri (to furnish with heddles)

no kiri kua.me

you furnish with heddles.IMP

You furnish the heddles.

kiri (poor)

ram kiri mosi

proper noun poor person.

'Ram is a poor man'.

5. tfijã (fish)

tfija zi.ho dumei

fish water.LOC stay.HABI

'Fish lives in water'.

t 1ijã (wife of younger brother)

t 1ijã.na zuha.be.

wife of younger brother.ACC call.IMP

'Call wife of younger brother'.

6. tiri (hang from a tree)

pops.ho titi tiri

tree.Loc seed hang

'The seed is hanging from the tree'.

tiri (banana)

iku.wa tiri hari

monkey.DET ${ }^{17}$ banana eat.PROG

'The monkey is eating banana'.

7. nini (drinking)

dip.a suze nini

grandfather.DET beer drink.PROG

'The grandfather is drinking beer'.

\footnotetext{
${ }^{17}$ Determiner
} 
nini (holding)

zin.a tfija ni.ni

grandmother.DET fish hold.PROG

'Grandmother is holding a fish'.

8. uzũ (navel)

mosi.jo uzũ muza du.me.i

people.GEN navel one EXIST ${ }^{18}$

'People have one navel'.

uzũ (bamboo tube)

uzu.ho t $\int u t \int a$ du.i

bambootube.LOC dryfish exist.IMP

There are dry fish in the bamboo tube.

9. garõ (throat)

a.jo garõ natoguri

I.GEN throat pain

'My throat is paining'.

garõ (pot)

hela du.za garõ

DET CLS ${ }^{19}$.one pot

'This is a pot'.

\section{Trisyllables}

1. kigari (peeling)

mousa.wa tiri.na kiga.ri

boy.CL banana.ACC peel.PROG

'The boy is peeling the banana'.

kigari (hanging)

joy.a kubi.na ber.ho kiga.ri

mother.DET basket.CL wall.LOc hang.PROG

'Mother is hanging the basket on the wall'.

${ }^{18}$ Existential marker

${ }^{19}$ Classifier 
2. gigari (to crow)

du giga.ri

cock crow.PROG

'The cock is crowing'.

gigari (to build house, platform)

ba ach giga.ri

he house build.PROG

'He is building house'.

3. nijani (cooking)

buzi.ja moko nija.ni

sister-in-law.DAT rice cook.PROG

'Sister-in-law is cooking rice'.

nijani (to rescue from water)

bou pu nija.ni

they wood rescue from water.PROG

'They are rescuing woods from water'

4. kusiri (whistle)

ba kusiri

$2^{\text {nd }}$ person singular whistle.PROG

'He is whistling'.

kusiri (medicine)

ba kusiri hari

$2^{\text {nd }}$ person singular medicine.PROG eat.PROG

'He is having medicine'.

\section{Appendix 3}

\section{Monosyllables}

1.t $\int u$ (pig)

ã t $\int u$ nina itfa.bem

I pig COMPL ${ }^{20}$ Say.PAST ${ }^{21}$

'I said pig'.

${ }^{20}$ Complementizer

${ }^{21}$ Past Tense 
$\mathrm{t} \int \mathrm{u}$ (to talk)

ã t $\int u$ nina itfa.bem

I talk COMPL say.PAST

'I said talk'.

2.t $\int \mathrm{i}$ (blood)

ã tfi nina itfa.bem

I blood COMPL Say.PAST

'I said blood'.

t $\mathrm{i}$ (to make)

ã tfi nina itfa.bem

I make COMPL say.PAST

'I said to make'.

3.ko (come)

ã ko nina itfa.bem

I come COMPL say.PAST

'I said come'.

ko (pluck)

ã ko nina itfa.bem

I pluck COMPL say.PAST

'I said pluck'.

4.li (necklace)

ã li nina itfa.bem

I necklace COMPLSay.PAST

'I said necklace'.

li (heavy)

ã li nina itfa.bem

I heavy COMPL say.PAST

'I said heavy'.

5.tu (oil)

ã tu nina itfa.bem

I oil COMPL Say.PAST

'I said oil'. 
tu (deep)

ã tu nina itfa.bem

I deep COMPL Say.PAST

'I said deep'.

\section{Disyllables}

\section{1.aku (ear)}

ã aku nina itfa.bem

I ear COMPL say.PAST

'I said ear'.

aku (upland)

ã aku nina itfa.bem

I upland COMPL Say.PAST

'I said upland'.

2.bari (garden)

ã bari nina itfa.bem

I garden COMPL Say.PAST

'I said garden'.

bari (to carry on back)

ã bari nina itfa.bem

I back.PROG COMPL say.PAST

'I said carry on back'.

3.tfitũ (old)

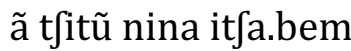

I old COMPL Say.PAST

'I said old'.

$\mathrm{t}$ fitũ (rope)

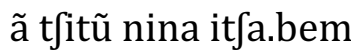

I old COMPL say.PAST

'I said rope'.

4.kiri (thread)

ã kiri nina itfa.bem

I thread COMPL say.PAST

'I said thread'. 
kiri (poor)

ã kiri nina itfa.bem

I poor COMPL say.past

'I said'.

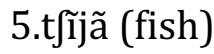

ã tfija nina itfa.bem

I fish COMPL say.PAST

'I said fish'.

t]ijã (wife of younger brother)

ã t ija nina itfa.bem

I wife of younger brother COMPL say.PAST

'I said wife of younger brother'.

6. tiri (hang from a tree)

ã ti.ri nina itfa.bem

I hang COMPL Say.PAST

'I said hang from a tree'.

tiri (banana)

ã tiri nina itfa.bem

I banana COMPL Say.PAST

'I said banana'.

7. nini (drinking).

ã nini nina itfa.bem

I drink.PROG COMPL Say.PAST

'I said drinking'.

nini(holding)

ã nini nina itfa.bem

I to hold COMPL say.PAST

'I said holding'.

8. uzũ (navel)

ã uzũ nina itfa.bem

I navel COMPL say.PAST

'I said navel'. 
uzũ (bamboo tube)

ũ uzũ nina itfa.bem

I bambootube say.PAST

'I said uzu'.

9. garõ (throat)

ã garõ nina itfa.bem

I throat COMPL say.PAST

'I said throat'

garõ (pot)

ã garõ nina itfa.bem

I pot COMPL say.PAST

'I said pot'.

\section{Trisyllables}

1. kigari (peeling)

ã kiga.ri nina itfa.bem

I peel.PROG compl say.PAST

'I said peeling'.

kigari (hanging)

ã kiga.ri nina itfa.bem

I hang.PROGCOMPL say.PAST

'I said hanging'.

2. gigari (to crow)

ã giga.ri nina itfa.bem

I crow.PROG COMPL Say.PAST

'I said crowing'.

gigari (to build house, platform)

ã gigari nina itfa.bem

I build.PROG COMPL say.PAST

'I said building'.

3. nijani (cooking)

ã nija.ni nina itfa.bem

I cook.PROGCOMPL Say.PAST

'I said cooking'. 
nijani (to rescue from water)

ã nija.ni nina itfa.bem

I rescue.PROG COMPL Say.PAST

'I said rescuing from water'.

4. kusiri (whistle)

ã kusiri nina itfa.bem

I whistle COMPL say.PAST

'I said whistle'.

kusiri (medicine)

ã kusiri nina itfa.bem

I medicine COMPL Say.PAST

'I said medicine'.

\section{References}

Abramson, Arthur S. 2004. The plausibility of phonetic explanations of tonogenesis. From traditional phonology to modern speech processing: festschrift for professor Wu Zongji's 95th birthday, 17-29.

Boersma, Paul \& David Weenink. 2013. Praat: doing phonetics by computer [Computer program]. Version 5.3.56. Online Resource: http://www.praat.org/ (12 March, 2016).

Brown, William B. 1895. An Outline Grammar of the Deori Chutiya Language Spoken in Upper Assam. Assam Secretariat Printing Office.

Burling, Robbins. 1959. Proto-Bodo. Language 35 (3), 433-453.

Burling, Robbins. 2003. Garo. In Thurgood, Graham \& LaPolla, Randy J (eds.) The Sino-Tibetan Languages, 387-400. London \& New York: Routledge.

Burling, R. 2003. The Tibeto-Burman Languages of North-eastern India. In Thurgood, Graham and LaPolla, Randy J. (eds.) The Sino-Tibetan languages, 169-192. London \& New York: Routledge.

Clements, G.N. and Goldsmith, J. (eds.) 1984. Autosegmental studies in Bantu tone. (Vol. 3). Walter de Gruyter.

Deori, Soranon. 2012. Deori vocabulary and terminology (Vol.1). Ajeevan Printers.

Goswami, Upendranath. 1994. An introduction to the Deuri language. Anundoram Borooah Institute of Language, Art and Culture, Assam.

Gussenhoven, Carlos. 2004. The phonology of tone and intonation. Cambridge: Cambridge University Press.

Hayes, Bruce. 1995. Metrical stress theory: principles and case studies. University of Chicago Press. 
Haudricourt, André G. 1954 De l'origine des tons en Vietnamien. Journal Asistique, 69-82.

Hyman, Larry. 2007. Tone: Is it Different? In John Goldsmith, Jason Riggle \& Alan Yu (eds.) The handbook of phonological theory, 2nd edn, 197-239. Blackwell.

Jacquesson, François. 2005. Le deuri: langue tibéto-birmane d'Assam 88. Leuven: Peeters Publishers.

Janhunen, J. 2008. Wutun. Lincom Europa.

Joseph, Umbavu V \& Robbins Burling. 2001. Tone correspondences among the Boro languages. Linguistics of the Tibeto-Burman area, 24(2), 41-55.

Lea, W.A. 1973. Segmental and suprasegmental influences on fundamental frequency contours. Consonant types and tone 1, p.15.

Matisoff, James A. 1973. Tonogenesis in Southeast Asia. In Larry M. Hyman (eds.), Consonant types and tone (Southern California Occasional Papers in Linguistics 1), 71-95. Los Angeles: University of Southern California.

Matisoff, James A. 2003. Handbook of Proto-Tibeto-Burman: System and Philosophy of Sino-Tibetan Reconstruction. Berkeley; Los Angeles: University of California Press.

Mazaudon, Martin. 1976. Tibeto-Burman tonogenetics. Linguistics of the Tibeto-Burman Area. Berkeley: University of California.

Moseley, Christopher (ed.). 2007. Encyclopaedia of the world's endangered languages. London and New York: Routledge.

Pham, H. 2005. Vietnamese tonal system in Nghi Loc. Toronto Working Papers in Linguistics 24.

Ratliff, Martha. 2015. Tonoexodus, tonogenesis, and tone change. In Patrick Honeybone \& Joseph Salmons. (eds.) The Oxford handbook of historical phonology, 245-261. Oxford: Oxford University Press.

Sarmah, Priyankoo. 2004. Some aspects of the tonal phonology of Bodo. Hyderabad. CIEFL MPhil dissertation.

Sarmah, Priyankoo. 2009. Tone Systems of Dimasa and Rabha: A Phonetic and Phonological Study. Florida. University of Florida PhD dissertation.

Sarmah, Priyankoo and Caroline Wiltshire. 2010. An acoustic study of Dimasa tones. In Stephen Morey and Mark Post (eds.). North east Indian linguistics 2, 25-44. Cambridge University Press India.

Schadeberg, T.C. 2009. Loanwords in Swahili. Loanwords in the world's languages: a comparative handbook, 76-102.

Shih, C.L. 1985. From tonal to accentual: Fuzhou tone sandhi revisited. In Annual Meeting of the Berkeley Linguistics Society. Volume 11, 316-326.

Thomas, Erik R. and Tyler Kendall. 2007. NORM: The vowel normalization and plotting suite. Online Resource: http://ncslaap. lib. ncsu. edu/tools/norm (15 June, 2016). 